\title{
Cognitive aspects of dietary assessment
}

\author{
By Elisabet Wirfält
}

\begin{abstract}
Imprecise dietary reports are often cited as one reason for weak or non-existent relations between diet and disease in epidemiological studies. Studies in applied cognitive psychology have contributed to the improved utility of general survey questionnaires. However, only a few studies have examined cognitive processes in diet recall, and the designs of dietary assessment instruments that may enhance recall of habitual diet. This paper briefly summarises some research on cognition in diet recall, and gives some suggestions for future research.
\end{abstract}

\section{Introduction}

Epidemiological studies depend on the ability of individuals to give clear reports of various life circumstances $(1,2)$, and sometimes of events from many years back (3-5). Dietary assessment in epidemiological studies is based on the assumption that individuals have clear memories of their usual dietary habits, and that these memories can readily be recalled and quantified (6). However, researchers have questioned whether the dietary assessment methods currently in use give exposure measures of satisfactory precision (79 ). The flaws of these methods are often cited as one reason for weak or non-existent relations between diet and disease in epidemiological studies $(9,10)$.

\section{Dietary methodological studies}

Food frequency questionnaires and diet history methods are methods commonly used in studies of diet and disease. These methods request individuals to recall complex information about their habitual diet (i.e., "usual" diet methods), such as the various types of foods eaten, the usual portion-sizes chosen, and the frequency of consumption (11). Methodological stu-

Elisabet Wirfält, MPH, $\mathrm{PhD}$, Lund University, The Malmö Diet and Cancer Study, Department of Medicine, Surgery and Orthopaedics, Claesgatan 7, SE-205 02 Malmö, Sweden.

E-mail:elisabet.wirfalt@smi.mas.lu.se

This article is based on a lecture held at the conference "Dietary assessments - how can we interpret the results?" The conference was arranged by Uppsala Food and Nutrition Centre (Uppsala Livsmedelscentrum) in Uppsala on Nov 11, 1997.

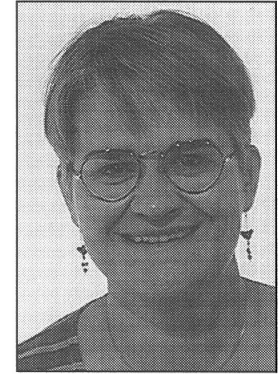

dies on dietary assessment have indicated that the specific format of an assessment method may result in differences in dietary reports. For instance, the reported intakes from food frequency questionnaires and diet history methods depend on the number of items included in the food list $(12,13)$, the general organisation of the food list (14), the grouping of food items (15), the order and type of frequency response alternatives $(16,17)$, and the number of portion-size alternatives presented $(13,18,19)$. Previous methodological studies have generally examined the ability of the instrument to estimate group mean intakes (i.e., instrument biases), and to rank individuals on energy and specific nutrients, but have generally not investigated the interplay between instrument design and cognitive processing in diet recall.

The difficulties in recalling and quantifying complex dietary information, and the ability of dietary assessment methods to provide accurate reports, have been much debated $(6,20)$. Also, researchers have reviewed and discussed cognitive issues related to dietary survey methods (21-23). However, only a few studies have examined the specific memory structures of dietary habits $(24,25)$, and the cognitive processes individuals use when recalling dietary memories $(24,26,27)$. Even fewer studies have examined how instruments should be designed to enhance cognitive processing in recall of habitual diet, and thus counteract misclassification and bias in dietary assessment $(24,28)$.

\section{Cognitive aspects of survey research}

Research concerned with the structure and design of survey questionnaires builds on theories of cognitive psychology $(1,29$, 30 ). During the last $10-15$ years survey researchers have become increasingly aware that analysis of the people's cognitive processes when they respond to questionnaire items can contribute to improved survey design and the reduction of response error $(24,30)$. Several researchers have suggested models that delineate the sequence of cognitive processes a respondent has to pass through when answering survey questions $(1,29)$. Although it is not well understood how many there are, the following classes have been identified as important for a respondent to go through when responding to a survey question. Also, the classes suggest the important steps to examine in cognitive studies of survey response (1).

1) Comprehending, or encoding, the presented question. The individual forms an internal representation of the question, and receives a signal to start retrieval from memory. Without thorough comprehension of the survey question, the appropriate memory cue is not received, relevant parts of memory will not be scanned, and the desired information may not be retrievable.

2) Decision and judgement processes. These processes guide the search for, and the output of, information from memory, and may be activated both before and after information is retrieved from memory. Decisions may include whether it is feasible or worth the effort to search for information. The respondent may decide that the survey question was not understood and will read the question once more. After retrieval, decisions may include judgement of accuracy, whether further retrieval attempts will be needed, or whether the answer should be altered to make it more socially desirable.

3) Retrieval of information from memory. The actual retrieval from memory may consist of recall of information that serves as a complete answer (in low-frequency behaviour). Alternatively, information may be recalled in incomplete fragments (in high-frequency behaviour, several similar memories may be available), 
which are then combined and adjusted via the decision process described above.

4) Response. The reverse of the first stage, i.e., information retrieved from memory needs to be re-coded into a verbal or written form

The model in Figure 1 describes how these classes of responses may be related (1). The model is intended to reflect that the retrieval of information, once a questionnaire item is understood, is not necessarily automatic. Control processes are hypothesised to occur both before and after retrieval from memory. Also, the sequence of events is flexible, and should not be seen as a strictly sequential processing chain.

\section{Cognitive aspects of dietary assessment}

Inspired by the results of general survey research, a project examining cognitive processes that facilitate dietary survey responding was initiated by Smith et al. (24). A series of experiments were designed to investigate the nature of the dietary information that is available in the memory of respondents, the ability of respondents to make food frequency judgements, the sensitivity of frequency judgements to retrieval cues, and the ability to judge portion-sizes in diet recall (24).

These experiments indicated that individuals largely appeared to rely on generic knowledge about their habitual diet when asked to recall dietary memories from longer periods. Although, specific memories from singular events clearly contributed to dietary reports, those memories were rapidly lost.

\section{Model}

A model (Figure 2) of the memory structure that explains reports about dietary habits was developed based on the experimental findings (31). This model proposes that individuals report their intake by searching a memory which consists of two classes of elements: permanent (or "generic") and episodic.

The permanent elements reflect the base rates of an individual's habitual food consumption. The permanent elements are labelled with category and item labels. Category labels could, for instance, be "foods I eat" or "foods I never eat", and item labels could be understood as common food or brand names, or the specific names individuals assign to foods. In addition to category and item labels, the episodic elements are labelled with contextual information from the episode when items were experienced. The reports of item labels of permanent elements are

Figure 1. Cognitive model of the survey response process.

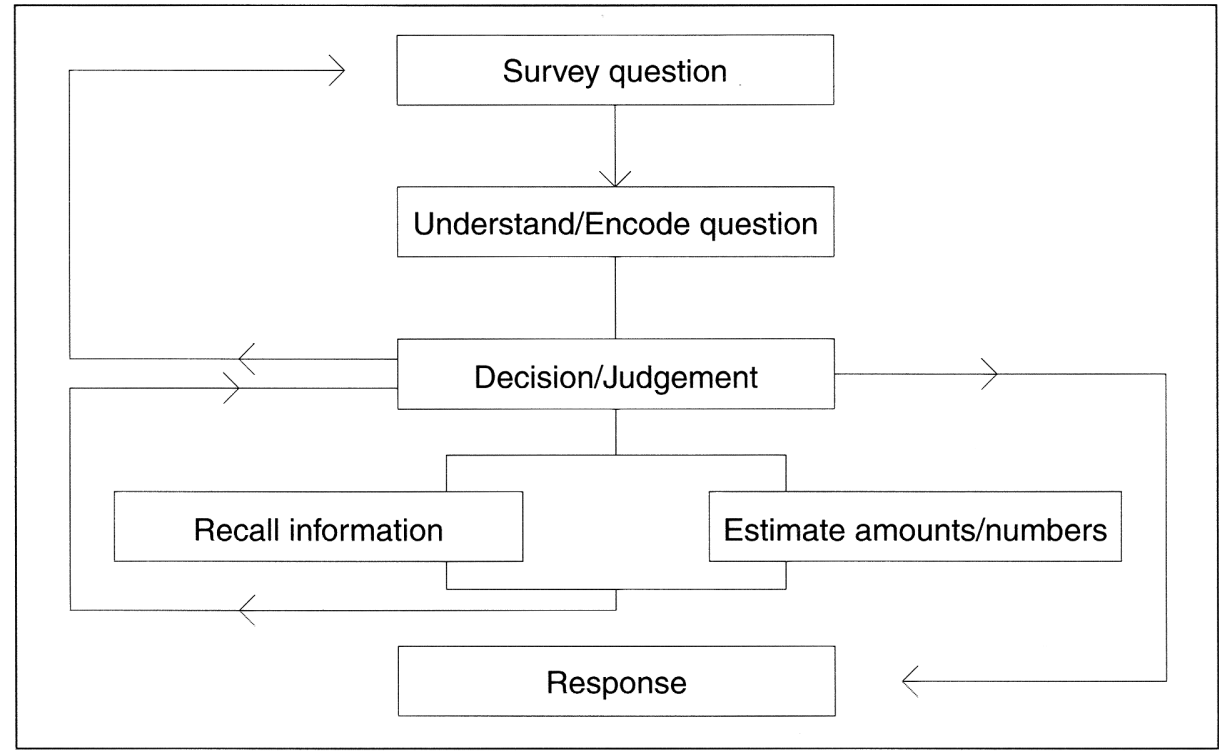

independent of time. However, the contextual information available in memory from the food consumption episode decays with time. When the contextual information is lost, recall of specific food memories is difficult. Therefore the quality of reports of item labels for episodic elements decreases with time.

The structure of habitual diet memories appears to be very similar to memories of other autobiographical events (24). Memories of similar incidents that occur repeatedly or every day, are superimposed on one another and will become confused over time . Individual events will be blurred with later events, and details will be lost, but a general pattern or "script" will be retained $(29,32)$. When recalling such memories inferences will commonly be made from episodic memories that appear salient to the respondent (32).

\section{Memory cues}

The important difference in recall processes and accuracy between "usual" diet methods (i.e., diet history methods and food frequency questionnaires) and "current" diet methods (i.e., 24-hour recalls) is not the closeness in time, or the number of details requested, but the cues presented to the respondent. A 24-hour recall interview is a true recall of distinct, discrete events in the very recent past. In this case the cue is a series of events within a well-defined time-interval. In contrast, the cues presented with a food frequency questionnaire are instead a series of food names. The respondent is requested to recognise these food names and relate them to personal habits. No assumption can be made that either recall or recognition give better, or "truer", dietary reports. Both processes probably use similar memory structures. However, the specific cues presented determine which aspect of the memory structure is accessed, or activated. The "trueness" of the report is much dependent on relevance of the cues given (31).

Smith et al. also conducted experiments with additional instructions given prior to the question asking individuals to recall foods consumed (33). These instructions added context to the recall process, and thus the experiment examined whether manipulations of the recall process would affect diet reports. When individuals were asked to report according to food groups, higher frequency rates were obtained compared to reports without such instructions. It is possible that reports were improved with food groups instructions, but the results could also indicate that these instructions increased the rate of intrusions (26). Most food frequency and diet history methods present food items in food group order. However, some studies have indicated that there may be more efficient ways of organising food lists in diet assessment. For instance, a study on food preferences noted, as a side finding, that study-participants discussed and organised their answers according to the type of meals they usually ate, and not according to food groups (34). In a study on reproducibility and accuracy of food frequency questionnaires a meal-ordered instrument performed better than an instrument organised according to food groups (35). A French study compared two versions of a diet history method with the same number of food items in both instruments (14). In one instrument foods were arranged according to generic food group order, and in the other according to 
Figure 2. Cognitive model of dieary habit memory structure.

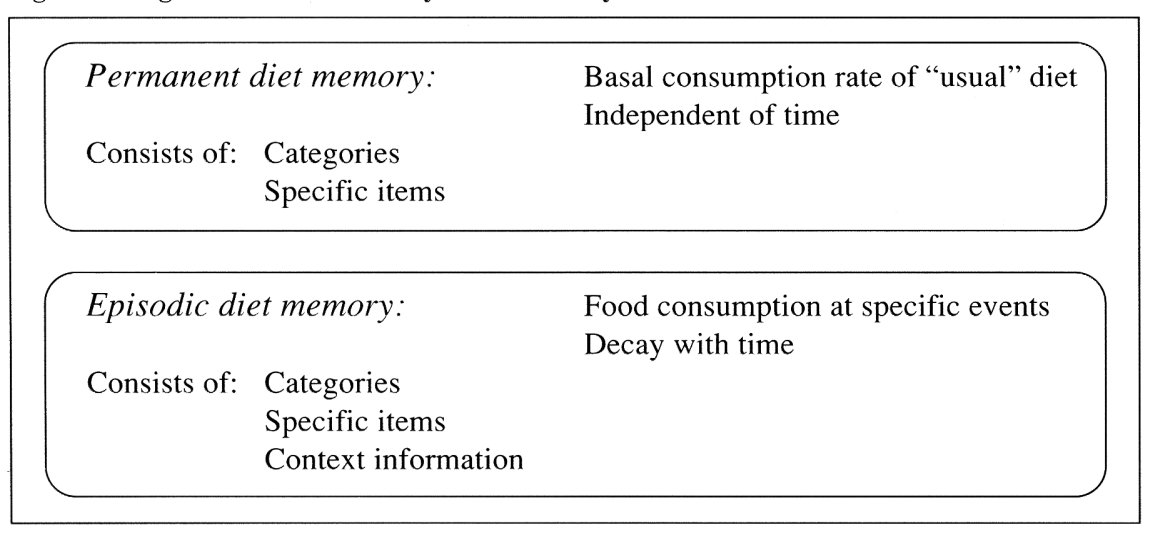

the types of meals in which the foods were usually consumed. In this population the food group version appeared to be less successful in ranking individuals on nutrient intakes than to the meal-ordered version (14).

In addition, a study that examined the perceptions of meaning of food frequency questionnaire items suggested that a number of changes could be made to provide more user-friendly memory cues (28). For instance, study participants preferred embedded questions, ranges of portion-sizes, questions about seasonal food consumption, inclusion of a "never" response category for frequency, disaggregation of foods with dissimilar eating patterns (i.e., tomato juice and tomatoes), unit-specific response categories for foods eaten primarily as units (e.g., eggs per week). The final questionnaire was long, but adjustments that increased page length often appeared to decrease interview time, because of better comprehension, easier retrieval, and fewer difficulties in formulating responses (28).

The importance of cues in dietary surveys is paralleled by findings from general survey research. For instance, a healthsurvey study indicated that recall of medical conditions among lay-persons was improved if questions were structured the same way respondents structured this information in memory (36). Thus the internal validity of questionnaires would likely increase if professional and scientific terms, which may not be fully understood by study participants, were avoided. Also, researchers working with populations of diverse ethnic backgrounds need to be sensitive to cultural differences, and ensure that questionnaire items are understandable and relevant to the examined population (37). Qualitative research methods are useful in the development of survey questionnaire questions (38). Qualitative inquiries will provide a deeper understanding of the circumstances that influence life events, thought processes and perceptions of respondents etc. (39), and consequently enhance the internal validity of the questionnaire. Qualitative approaches have rarely been used in the development of dietary assessment methods, but may be useful to identify memory cues that potentially could enhance recall of habitual diet.

\section{Frequencies or portion-sizes?}

The experiments conducted by Smith et al. indicated that frequency judgements of individuals were reasonably accurate and reflected a sensitivity to the rates of consumption. However, frequency judgements between individuals had much lower accuracy, probably due to lack of a common standard between study participants. Consider the consumptions of two individuals, $\mathrm{A}$ and $\mathrm{B}$, as an illustration of these observations. A consumed boiled potatoes 9 times, and fried potatoes 6 times during a one-month period. $\mathrm{B}$ ate boiled potatoes 6 times and fried potatoes 9 times during the same period. When asked to recall their consumptions $\mathrm{A}$ reported having eaten boiled potatoes 11 times and fried potatoes 8 times, while the reported consumption of B was 5 times for boiled potatoes and 8 times for fried potatoes. The reported frequencies are not accurate in absolute terms, but within individuals the ranking of reported frequencies is similar to the "true" consumption. However, across individuals only the reported frequencies of boiled potatoes correspond reasonably well with the actual consumption (40).

"Never" and "daily" consumptions are probably judged with fair accuracy. However, correct accounts of sporadic consumptions may be more difficult. Cognitive research has shown that frequency judgements are commonly inferred from episodic memories. For example unique events, recent events, or frequent events may be overestimated because they are easy to remember and therefore judged more salient than others (29).

An issue of concern in dietary assessment is the estimation of portion-sizes.
The studies conducted by Smith et al. indicated that individuals lack stable longterm memories for the quantities of food they eat. However, the experiments also indicated that when food models were used the best estimates were obtained shortly after the judged food portion was viewed (24). These findings may indicate that recall of food portions has some accuracy in 24-hour interviews, but is more unreliable in "usual" diet assessment. A methodological study that examined total variation of diet made similar observations (41). Many foods had large variations in portion-sizes, which made it difficult to identify a typical or "usual" portion-size.

Although, the ability to estimate "usual" portion-sizes appears to be limited, and the assessment of frequencies appears to be of the greatest importance when ranking individuals on dietary intakes (41-43), studies still suggest that frequency estimates alone are not sufficient for ranking on macro-nutrients in particular $(19,44-$ 47). When using standard portion-sizes in nutrient intake calculations, some of the discriminating ability will be removed (48). Even if individuals do not have true "usual" portion-sizes for many foods, it may still be worthwhile to ask for portionsize information, if this will contribute to a clearer separation of individuals into different intake categories (49).

\section{Conclusions}

The issues raised above can be summarised as follows: 1) The specific cues presented (in a questionnaire or an interview) determine what an individual will report about her/his dietary habits. 2) Memories of "usual" dietary habits are stored as permanent, or "generic" memories. However, the generic knowledge about individual dietary habits contributes significantly to reports about dietary intake during specific reference periods. 3) Episodic food memories influence the long-term, or "usual", diet reports. Food consumption reports are commonly influenced by memories from unique events, from recent events, and from frequent events, because such food consumption memories are often judged as more salient than others. 4) Individuals are quite capable of reporting consumption frequencies which are consistent within individuals. However, the quality of absolute food frequency estimates is lower than that of relative estimates, probably due to poor calibration among individuals. 5) Food frequency reports are influenced by the instructions given prior to recall. This indicates that questionnaires with relevant memory cues may prompt individuals to provide diet reports of higher fidelity. 
A general conclusion from the work of Smith et al. appears to be that "usual" diet methods are reasonable methods in dietary assessment, because "if average dietary intake is what people can report about then maybe that is what they should be asked about" (31). Also, the calibration of food consumption frequencies among individuals needs to be emphasised in the future development of dietary assessment methods. Food frequency questionnaires request individuals to estimate frequencies of consumption from long lists of foods, many of which are rarely eaten.
Smith et al. therefore suggest that free reports of habitual diets followed by calibrated frequency estimates, as a follow-up, may considerably improve the efficiency of nutritional surveys. Crosschecking questions of frequency responses have previously been used by re-searchers as a way to adjust food consumption frequencies, and to counteract the overestimating effect of long food lists (13).

Other researchers have requested respondents to report the relative consumption frequency, i.e., "Out of 10 fruits how many are oranges, apples ... etc.?", instead of using food lists with uniform frequency response alternatives (49). Such approaches, and others based on findings from studies in applied cognitive psychology, need to be further developed and evaluated for their efficiency in ranking individuals when incorporated into an instrument. The potential of reducing the burden placed on respondents, and counteracting high dropout rates and non-responses in dietary surveys, should strongly motivate nutrition epidemiologists to emphasise cognitive aspects in the future development of dietary assessment instruments.

\section{References}

1 Willis GB, Royston P, Bercini D: The use of verbal report methods in the development and testing of survey questionnaires. Appl Cogn Psych 1991:5:251-67.

2 Kelsey JL, Thompson WD, Evans AS: Methods in observational epidemiology. New York Oxford: Oxford University Press,1986;309-36.

3. Kuzma JW, Lindsted KD: Determinants of long-term (24-Year) Diet recall ability using a 21 -item food frequency questionnaire. Nutr Cancer 1989;12:151-160.

4. Dwyer JT, Gardner J, Halvorsen K, Krall EA, Cohen A, Valadan I: Memory of food intake in the distant past. Am J Epidem 1989;130:1033

5 Friedenreich CM, Slimani N, Riboli E: Measurements of past diet: Review of previous and proposed methods. Epidem Rev 1992; 14:177-96.

6. Sempos CT: Invited commentary: Some limitations of semiquantitative food frequency questionnaires. Am J Epidem 1992;135:1127-32.

7. Beaton GH: Approaches to analysis of dietary data: relationship between planned anlysis and choice of methodology. Am J Clin Nutr 1994; 59(suppl):253S-261S

8. Liu K: Statistical issues related to semiquantitative food-frequency questionnaires. Am J Clin Nutr 1994;59(suppl):262S-265S.

9. Prentice RL: Measurement error and results from analytic epidemiology: Dietary fat and breast cancer. J Natl Canc Inst 1996;88:17381747.

10. Boyd NF, Martin M, Noffel GA, Lockwood GA, Trichler DL: A meta-analysis of studies of dietary fat and breast cancer risk. $\mathrm{Br} \mathrm{J}$ Canc 1993;68:627-636.

11. Dwyer JT: Assessment of dietary intake. In: Shils ME, Olson JA, Shike M, eds. Modern nutrition in health and disease. Philadelphia: Lea and Febiger, 1994:842-860.

12. Krebs-Smith SM, Heimdinger J, Subar AF, Patterson BH, Pivonka E: Using food frequency questionnaires to estimate fruit and vegetable intake: association between the number of questions and total intake. J Nut Educ 1995 ;27:80-85.

13. Block G, Hartman AM, Naughton D: A reduced dietary questionnaire: Development and validation. Epidem 1990;58-64.

14. Boutron MC, Faivre J, Milan C, Lorcerie B, Esteve J: A comparison of two diet history questionnaires that measure usual food intake. Nutr and Cancer 1989;12:83-91.

15. Serdula M, Byers T, Coates R, Mokdad A, Simoes E, Eldridge L: Assessing consumption of high-fat foods: the effect of grouping foods into single questions. Epidemi 1992;3:503-508.

16. Wolk A, Bergström R, Adami H, et al: Selfadministered food frequency questionnaire:the effect of different designs on food and nutrient intake estimates. Internat J Epidem 1994; 23:570-576.

17. Tylavsky FA, Sharp GB: Misclassification of nutrient and energy Intake from use of closed- ended questions in epidemiologic research. Am J Epidem 1995;142:342-352i

18. Block G, Hartman AM, Dresser CM, Carroll MD, Gannon J, Gardner L: A data-based approach to diet Questionnaires Design and Testing. Am J Epidem 1986;124:453-469.

19. Kristal AR, Beresford SAA, Lazovich D Assessing change in diet-intervention research. Am J Clin Nutr 1994;59:185S-189S.

20 Briefel RR, Flegal KM, Winn DM, Loria CM, Johnson CL, Sempos CT: Assessing the nation's diet: Limitations of the food frequency questionnaire. J Am Diet Assoc 1992:92:959-962.

21. Krall EA, Dwyer JT, Coleman KA: Factors influencing accuracy of dietary recall. Nutr Res 1988;8:829-841.

22. Dwyer JT, Krall EA, Coleman KA: The problem of memory in nutritional epidemiology research. J Am Diet Assoc 1987;87:1509-1512.

23. Dwyer JT, Coleman KA: Cognitive issues in two dietary survey methods. In: Wright JD, Ervin B, Briefel RR, eds. Consensus workshop on dietary assessment: Nutrition monitoring and tracking the year 2000 objectives. Hyattsville, Maryland: U.S. Department of Health and Human Services, 1994:98-115.

24. Smith AF: Cognitive processess in long-term dietary recall. Vital Health Stat 1991;6:4

25. Baranowski T, Domel SB: A cognitive model of children's reporting of food intake. Am J Clin Nutr 1994;59(suppl):212S-217S.

26. Fischer RP, Quigley KL: Applying cognitive theory in public health investigations: Enhancing food recall with the cognitive interview. In: Tanur JM ed Questions about questions. Inquiries into the cognitive basis of surveys. New York: Russel Sage Foundation, 1992:154-69.

27. Domel SB, Thompson WO, Baranowski T, Smith AF: How children remember what they have eaten. Journal of the Am Diet Assoc 1994; 94:1267-72

28. Subar AF, Thompson FE, Smith AF, et al: Improving food frequency questionnaires: A qualitative approach using cognitive interviewing. J Am Diet Assoc 1995; 95:781-8.

29. Tourangeau R. Cognitive sciences and survey methods: In: Jabin TB, Straf ML, Tanur JM, Tourangeau R, eds. Cognitive aspects of survey methodology: building a bridge between disciplines. Washington DC: National Academy Press, 1984:73-100.

30. Jobe JB, Mingay DJ: Cognitive research improves questionnaires. Am J Publ Health 1989; 79:1053-5.

31. Smith AF, Jobe JB: Validity of reports of longterm dietary memories:data and a model. In: Schwarz N, Sudman S, eds. Autobiographical memory and the validity of retrospective reports. New York Berlin Heidelberg London Paris Tokyo HongKong Barcelona Budapest: Springer-Verlag, 1997:140 pp.

32. Bradburn NM, Rips LJ, Shevell SK: Answering autobiographical questions: The impact of me- mory and inference on surveys. Sci 1987; 236:157-61.

33. Smith AF, Jobe JB, Mingay DJ: Retrieval from memory of dietary information. Appl Cognitive Psychol 1991;5:269-96.

34. Rappoport L, Peters GR, Huff-Corzine L, Downey R: Reasons for eating: An exploratory cognitive analysis. Ecol Food Nutr 1992; 28:171-89.

35. Smith-Barbaro P, Darby L, Reddy BS: Reproducibility and accuracy of a food frequency questionnaire used for diet intervention studies. Nutr Res 1982;2:249-61.

36. Brewer MB, Dull VT, Jobe JB: Social Cognition Approach to reporting chronic conditions in health surveys. Vital Health Stat 1989; 6:1-28.

37. Cassidy CM: Walk a mile in my shoes: culturally sensitive food-habit research. Am J Clin Nutr 1994;59(suppl):190S-197S

38. Black N: Why we need qualitative research. J Epidem Comm Health 1994;48:425-7.

39. Patton MQ: The Nature of qualitative inquiry. In: Anonymous 2nd ed. Newbury Park London New Delhi: SAGE Publications, 1991:9-34.

40. Smith AF: Cognitive psychological issues of relevance to the validity of dietary reports. Eur J Clin Nutr 1993;47:S6-S18.

41. Hunter DJ, Sampson L, Stampfer MJ, Colditz GA, Rosner B, Willett WC: Variability in portion sizes of commonly consumed foods among a population of women in the United States. Am J Epidem 1988;127:1240-9.

42. Flegal KM, Larkin FA: Partitioning macronutrient intake estimates from a food frequency questionnaire. Am J Epidem 1990;131:1046-58.

43. Flegal KM, Larkin FA, Metzner HL, Thompson FE, Guire KE: Counting Calories: Partitioning Energy Intake Estimates from a Food Frequency Questionnaire. Am J Epidem 1988; 128 749-60.

44. Chu SY, Kolonel LN, Hankin JH, Lee J: A comparison of frequency and quantitative dietary methods for epidemiologic studies of die and disease. Am J Epidem 1984;119:323-34

45. Samet JM, Humble CG, Skipper BE: Alternatives in the collection and analysis of food frequency interview data. Am J Epidem 1984; 120:572-81.

46. Pietinen P, Hartman AM, Haapa E, et al: Reproducibility and validity of dietary assessment Instruments. II. A Qualitative Food Frequency Questionnaire. Am J Epidem 1988;128:667-76.

47. Wirfält AKE, Jeffery RW, Elmer PJ: The reduced Block and Willett food frequency questionnaires differ in their ability to discriminate nutrient intakes. Am J Epidem (In press).

48. Margetts BM, Nelson M: Design concepts in epidemiology. Oxford New York Tokyo: Oxford University Press, 1991.

49. Lindroos A-K, Lissner L, Sjöström L: Validity and reproducibility of a self-administered dietary questionnaire in obese and non-obese subjects. Eur J Clin Nutr 1993;47:461-81. 